\title{
VIOLÊNCIA CONTRA A MULHER E DESIGUALDADE DE GÊNERO NA ESTRUTURA DA SOCIEDADE: DA SUPERAÇÃO DOS SIGNOS PELA ÓTICA DAS RELAÇÕES DE PODER
}

\author{
Michelle Ângela Zanatta ${ }^{1}$ \\ Josiane Petry Faria ${ }^{2}$
}

\section{RESUMO}

Estuda-se a ressignificação do gênero na sociedade, desmistificando-o a partir da análise do poder para discutir a base de fundamentação da desigualdade de gênero que deriva na violência contra a mulher. Pelo método dedutivo, investiga-se a transformação da concepção de gênero e sexo, abordam-se as nuances do poder e sua circularidade no gênero e as questões de dominação-submissão e estratégias de empoderamento para conscientização e enfrentamento da violência contra a mulher. Conclui-se que no jogo social a desigualdade de gênero e a violência contra mulher repousam sobre o capitalismo excludente, indicando que a ruptura perpassa por políticas públicas diversas.

PALAVRAS-CHAVE: Desigualdade; gênero; relações de poder; violência de gênero.

\section{VIOLENCE AGAINST WOMEN AND GENDER INEQUALITY IN THE STRUCTURE OF SOCIETY: THE OVERCOMING OF SIGNS BY THE VIEW OF POWER RELATIONS}

\begin{abstract}
The gender resignification in society is studied, demystifying it from the analysis of power to discuss the basis of the foundation of gender inequality that derives from violence against women. Through the deductive method, the transformation of the conception of gender and sex is investigated, the nuances of power and their circularity in the genre are discussed, as well as the issues of domination-submission and empowerment strategies for raising awareness and coping with violence against women. It's concluded in the social game gender inequality and violence against women rests on exclusionary capitalism, indicating that the rupture runs through public policies.
\end{abstract}

KEY WORDS: Inequality; genre; Power relations; gender violence.

\section{INTRODUÇÃO}

$\mathrm{Na}$ expectativa de compreender a violência de gênero e ainda a violência doméstica, bem como a dificuldade de superação de um cenário irracional de desconsideração e

\footnotetext{
${ }^{1}$ Mestranda em Direito pelo Programa de Pós-Graduação Strictu Sensu da Universidade de Passo Fundo (UPF). Especialista em Direito Processual Civil pela PUC/SP (2011). Graduada em Direito (2006) e Psicologia (2008) pela URI - Campus de Erechim/RS. e-mail: mazanatta@ yahoo.com.br.

${ }^{2}$ Doutora em Direito pela Universidade de Santa Cruz do Sul (2015) com bolsa Prosup e PDSE Capes na Universidade de Sevilla/ES (2015). e-mail projurmulher@upf.br.
} 
subjugação da mulher presente até a contemporaneidade, o estudo mostra-se vinculado aos problemas de seu de tempo e dada à multifatoriedade de causas dessa violência específica não nega a função social das ciências jurídicas no entendimento e tratamento da questão.

Ciente que a sociedade resiste à transformação e à ressignificação de papéis sociais, sobretudo a partir da tomada de consciência a respeito do emprego das estratégias de normalização e naturalização da violência contra a mulher, o artigo traz observações fulcradas das dimensões e relações do poder. A partir daí desmistifica a distribuiç̧ão biológica das posições de poder e, principalmente, desvela a casa, a família como espaço seguro de proteção e aconchego.

Para essas reflexões se divide em três partes, para melhor dialogar sobre a transmutação da categoria gênero e como esse signo foi sendo revisitado historicamente, influenciado diretamente pela exposição das relações de poder. Temática essa que aparecerá desnuda e em conexão com gênero na segunda parte, onde tratar-se-á não de conceitos, mas de desvelamento da circularidade do poder e das estratégias de manutenção da desigualdade. Por fim, enfrentará a violência contra a mulher e desmistificará a simplicidade do tema, revelando a permeabilidade da desigualdade de gênero na manutenção da estrutura social.

\section{RELAÇÕES DE GÊNERO: SIGNO DE RELEVÂNCIA TEÓRICA E POLÍTICA}

Para estudar a violência contra a mulher é fundamental o entendimento do conceito de gênero. Neste sentido, é recente o emprego do termo gênero para designar as diferenças entre homens e mulheres. Sua introdução nas pesquisas de diversas áreas reporta à segunda metade do século XX, quando eclodiram os movimentos feministas. Varikas (1989) afirma que ao tomar emprestado o termo da gramática e da linguagem, as feministas postularam a necessidade de superar o sexo biológico do sexo social, produto de uma construção social permanente, que forma em cada sociedade humana, a organização das relações entre os homens e as mulheres.

Lauretis (1994) entende o termo gênero como a representação de uma relação, a relação de pertencer a uma classe, um grupo, uma categoria. Assim, gênero representa não um 
indivíduo e sim uma relação, uma relação social; em outras palavras, representa um indivíduo por meio de uma classe.

De acordo com Oliveira e Knöner (2005), a utilização do conceito de gênero proporcionou o afastamento da ideia de determinismo biológico relativa ao sexo. Essa categorização, na visão de Dezin (1995, citado por NOGUEIRA, 2001), possibilita a construção de significados sociais e culturais que distinguem cada categoria anatômica sexual e que são repassados aos indivíduos desde a infância.

Dessa forma, o gênero feminino só se constrói em oposição ao gênero masculino e, nas diferenças, homens e mulheres se constroem juntos. Portanto, o significado de gênero implica um conceito de relação, uma vez que o universo das mulheres está inserido no universo dos homens e vice-versa. Deste modo, o gênero dá-se apenas nas relações que não acarretam desigualdade ou poder. (PRAUN, 2011)

Sartori (2004, citado por OLIVEIRA e KNÖNER, 2005) também menciona que o gênero constitui uma construção social, abordando as relações de poder entre homens e mulheres. Sendo que a forma como tais vínculos se estabelecem variam em diferentes sociedades e culturas, até mesmo dentro de uma mesma sociedade. Ou seja, as relações de poder entre homens e mulheres não são fixas e são construídas pelas sociedades.

Neste mesmo sentido preconiza Heberle (2001, p. 98),

Gênero constitui uma categoria socialmente construída, que interage com outras variáveis socioculturais e contextuais, como nível de escolaridade, situação socioeconômica, idade, etnia, classe social, orientação sexual, filiação política e religiosa e relação de poder.

Nas palavras de Cabral e Díaz (1998) gênero é tido como relações sociais desiguais de poder entre homens e mulheres que são o resultado de uma construção social do papel do homem e da mulher a partir das diferenças sexuais.

Rubin (1975, p.159) reporta-se à categoria gênero como o sistema sexo/género, definindo-a como "el conjunto de arreglos por medio de los cuales una sociedad transforma la sexualidad biológica en productos de la actividad humana y dentro de los cuales estas necesidades sexuales transformadas son satisfechas". De acordo coma autora (1975, p.204) 
“los sistemas de sexo/género [...]; son productos de la actividad humana histórica".

Por conseguinte, gênero retrata um signo que se tornou teórica e politicamente relevante desde a década de 70 do século XX quando, sob a influência do movimento feminista e de expressiva revolução de paradigmas nas ciências, expandiu seu conceito inicial de uma classe de algo ou de seres, para denominar uma classe de seres humanos, configurando-se dali em diante como uma definição de extenso valor para a compreensão da identidade, papéis e relações entre homens e mulheres, nas sociedades modernas. (ANDRADE, 2004)

Desta forma, segundo a autora citada (2004), será possível diferenciar sexo, pois biológico e gênero, pois social e, com isto, ressignificar a dicotomia homem/mulher, feminino/ masculino, descontruindo o modelo androcêntrico de sociedade e de saber e os mecanismos que, a um só tempo, asseguravam e ocultavam a dominação masculina, mantendo a diferença de gênero ignorada.

Portanto, o gênero, na perspectiva conservadora, é sinônimo de sexo e estaria adstrito ao código binário estabelecido. Já numa perspectiva crítica, apoia-se em elementos socioculturais e sobretudo no modo da pessoa se interpretar no contexto fisio-biológicopsicológico. Nessa ótica, o gênero é mais amplo que as categorias fornecidas pela interpretação do sexo, isto é, masculino e feminino não são suficientes para definir o gênero, o qual não pode ser resolvido definitivamente quando do nascimento. $O$ tempo do gênero é diferente do tempo do sexo. (FARIA, 2017)

Com efeito, para além do dado biológico que define o sexo (cada nascimento requer um registro sexual), o gênero será concebido como o sexo socialmente construído (ANDRADE, 2004). Neste sentido, é que Scott (1995) preconiza que o termo em estudo se apresenta como uma forma de construção cultural - a criação inteiramente social de ideais sobre os papéis adequados aos homens e às mulheres.

Mostra-se constante nas análises e na compreensão das sociedades um pensamento dicotômico e polarizado sobre os gêneros; usualmente se concebem homem e mulher como polos opostos que se relacionam dentro de uma lógica invariável de dominação-submissão. (SCOTT, 1995) 
porque ele próprio é uma atividade criadora ocorrendo incessantemente [...] o gênero é uma maneira contemporânea de organizar normas culturais passadas e futuras, um modo de a pessoa situar-se em e através destas normas, um estilo de viver o corpo no mundo. [...] o gênero é uma maneira de existir do corpo e o corpo é uma situação, ou seja, um campo de possibilidades culturais recebidas e reinterpretadas. O corpo de uma mulher é essencial para definir sua situação no mundo. Contudo, é insuficiente para defini-la como mulher. Esta definição só se processa através da atividade desta mulher na sociedade. Isto equivale dizer [...] que o gênero se constrói - expressa através das relações sociais. (SAFFIOTI, 1992, p. 189)

Visto que o gênero se constrói socialmente, não possuindo uma origem que possa ser definida ao ser significado através do tempo, propõe-se apresentar as nuances do poder e sua peculiar circularidade no que se relaciona ao termo.

\section{GÊNERO E PODER: AS DIMENSÕES DA DESIGUALDADE}

O conceito de poder atrelado à discussão das relações de gênero torna-se substancial na compreensão da desigualdade de gênero, desmistificando a oposição entre dominadores, os homens, e dominadas, as mulheres. Assim, a categoria poder torna-se primordial na discussão, contudo não é qualquer aporte teórico que consegue evidenciar as nuances que encobre as relações desiguais entre homens e mulheres, estando imersas pelas relações de poder. (SAFFIOTI, 2004)

As transformações das tecnologias do poder estudadas e analisadas por Foucault ajudam a compreender o que é ser homem e mulher nas sociedades, bem como os mecanismos de poder contribuem para a afirmação das desigualdades de gênero.

Homens e mulheres certamente não são construídos apenas através de mecanismos de repressão ou censura, eles e elas se fazem, também, através de práticas e relações que instituem gestos, modos de ser e de estar no mundo, formas de falar e de agir, condutas e posturas apropriadas (e, usualmente, diversas). Os gêneros se produzem, portanto, nas e pelas relações de poder. (LOURO, 1997, p.41)

A partir dessa concepção, o poder é exercido, podendo ele ser contestado, aceito, resistido e absorvido. Dessa maneira, tal entendimento contraria aqueles que acreditam ser apenas o Estado único detentor de poder e sinaliza que o exercício do poder pressupõe 
que ele circula nas relações sociais, penetrando-as sutilmente. (QUEIROZ,2008)

Assim, no seio das relações de poder manifestam-se desigualdades e diferenças, expressas nas análises das categorias de gênero, classe social, sexualidade e raça/etnia, que são demarcadas historicamente por hierarquias, violências, discriminação e desigualdades, já que o poder pode se revelar de maneira sutil e invisível, e no caso das relações de gênero acarreta malefícios a algumas mulheres quando expresso pelas várias manifestações da violência. (COSTA; MADEIRA; SILVERA, 2012)

O poder se expressa nas dimensões macro e micro, adequando-se mais esse conceito para se analisar as relações de gênero, pois a mulher mesmo obtendo uma pequena parcela do poder conferido socialmente em maior escala aos homens, não deixa de exercer poder. A mulher não é por natureza dominada, pois oferece resistências às situações impostas, isto estimula a perceber que a mulher possui seu campo de poder e o exerce também, mesmo em graus menores. (FOUCAULT, 1979)

Segundo Scott (1995, p.86), “[...] é preciso substituir a noção de que o poder social é unificado, coerente e centralizado por algo como o conceito de poder de Michel Foucault, entendido como constelações dispersas de relações desiguais, discursivamente constituídas em 'campos de forças' sociais".

As relações de gêneros são dialéticas, refletindo contradições e concepções diferenciadas de gênero internalizadas por diferentes atores sociais de ambos os sexos. Quando se trabalha com a categoria relações de gênero deve-se entender que mulheres e homens vivenciam relações e experiências distintas, haja vista que na sociedade contemporânea não existe igualdade de gênero. (COSTA; MADEIRA; SILVERA, 2012)

As relações de poder entre homens e mulheres, embora recorrentes, serão sempre carregadas de sentidos próprios de cada sociedade e de seu tempo. Além disso, deve-se pensar que essas relações não se caracterizariam como de mão única, tanto porque o movimento se exerce nas duas direções entre os gêneros, quanto porque ele é atravessado por outras disputas, provenientes de outros campos de força que não o do gênero. (SCOTT, 1995)

Perrot (1988) vê nas relações, a possibilidade das mulheres exercerem poderes, o que relativiza o poder dos homens, ressaltando que não existe uma passividade por parte das mulheres quanto a uma dominação total. No entanto, elenca algumas referências tradicionalmente admitidas sobre essa divisão de poderes: os homens teriam o poder de 
Estado, o poder político, o poder das decisões e do espaço público, e as mulheres teriam os poderes informais, os poderes domésticos, dos bastidores, das influências etc. Nestas situações, ainda que de naturezas diferentes, pode-se admitir que os dois gêneros têm poder.

As relações entre homens e mulheres podem então ser percebidas como relações de poder na medida em que sejam relações entre sujeitos livres e, portanto, que suponham resistências, respostas, reações, transformações (LOURO, 1997). É preciso pensar que todas essas ações se dão de modo diversificado segundo os gêneros, ou seja, se homens e mulheres estão envolvidos nessas múltiplas relações e, portanto, se ambos sofrem seus efeitos, deve-se lembrar que elas são vividas de modos diferentes por cada um deles.

Ser do gênero feminino ou masculino implica em perceber e estar no mundo de modos diferentes, do ponto de vista concreto e simbólico. Isto leva Scott (1995, p.88) a dizer que há um controle ou um acesso diferencial aos recursos materiais e simbólicos e que isso supõe entender que "o gênero torna-se implicado na concepção e na construção do próprio poder $[\ldots] . "$

Desta forma, pode-se inferir que as relações de poder são expressas através das relações de gênero, interpondo as relações sociais, sejam de classe, orientação sexual e/ou etnia (COSTA; MADEIRA; SILVERA, 2012). Ou seja, as relações de poder estão presentes nos dois gêneros humanos, porém, em diferentes graus e dimensões desiguais (TORRES, 2001). Ressalte-se que, em nenhum caso, essa diferença é entendida numa relação de hierarquia, mas sim, numa relação contraditória entre homens e mulheres.

Para Scott (1995), o gênero é um elemento constitutivo de relações sociais baseadas nas diferenças percebidas entre os sexos e o gênero é uma forma primária de dar significado às relações de poder. Ou seja, o gênero é um campo primário no interior do qual, ou por meio do qual, o poder é articulado. O gênero não é o único campo, mas ele parece ter sido uma forma persistente e recorrente de possibilitar a significação do poder no ocidente, nas tradições judaico-cristãs e islâmicas.

Deve-se atentar, contudo, para a dominação nas relações de gênero não assumir só o aspecto masculino. Existe a dominação da mulher sobre a mulher, à medida que esta, sem perceber as contradições das ideias absorvidas no processo cultural, acaba estabelecendo concorrência com outras mulheres, legitimando, muitas vezes, as relações de reprodução da 
ideologia dominante sob a ótica da assimetria entre os sexos e também dentro do mesmo sexo. (TORRES, 2001)

O "gênero tanto é um elemento constitutivo das relações sociais fundadas sobre as diferenças percebidas entre os sexos, quanto uma maneira primária de significar relações de poder" (SCOTT, 1995, p.86). Tal definição comporta duas proposições essenciais: na primeira parte, o processo de constituição dessas relações e, na segunda, a dimensão do poder. Nesta, o gênero é o primeiro meio através do qual o poder é articulado.

Para Scott (1995, p. 16), "estabelecidos como um conjunto de referências, os conceitos de gênero estruturam a percepção e a organização simbólica de toda a vida social" e "na medida em que estas referências estabelecem distribuições de poder o gênero torna-se envolvido na concepção e na construção do poder em si mesmo".

Tal definição permite compreender que o gênero constitui-se através de complexas relações sociais de legitimação e construção recíproca. Enfim, os gêneros se produzem, portanto, nas e pelas relações de poder. (LOURO, 1997). Em outras palavras, o gênero tornase implicado na concepção e na construção do próprio poder. (SCOTT, 1995) Assim, gênero não reflete a realidade biológica, mas sim, constrói o sentido dessa realidade.

Mostra-se prudente utilizar a categoria de gênero associada ao conceito de patriarcado, pois este indica as relações de dominação-submissão e o modo como elas se estabeleceram. Neste modelo de família, os atributos e os papéis de gênero valorizam o homem em detrimento da mulher, legitimando, por um lado, a dominação do homem e por outro, a inferioridade da mulher. Nesta perspectiva, a mulher é destituída de autonomia e do direito de decidir, inclusive sobre o seu próprio corpo. (SAFFIOTI, 2004) Desta forma, a introdução da categoria gênero foi fundamental para perceber as relações de violência no espaço familiar, uma vez que esta categoria possibilita compreender os papéis socialmente pré-definidos para homens e mulheres, como perpetradores de relações hierárquicas desiguais. (GOMES; DINZ; ARAUJO e COELHO, 2007).

Alberdi e Matas (2002) preconizam que para entender a denominação de violência de gênero é preciso ter em conta o caráter social dos traços atribuídos a homens e mulheres já que a maioria dos traços do feminino e do masculino são construções culturais, são produtos da sociedade e não derivados necessariamente da natureza. De outra banda, Strey (2001) esclarece que reunir os conceitos violência e gênero para transformá-los em um terceiro 
conceito não se apresenta como uma tarefa complicada, na medida em que o conceito de gênero já pressupõe, por princípio, uma certa quantidade de pressão sobre os indivíduos para conformarem-se aos padrões culturais sobre o que seja ser homem ou mulher. Além do mais, como visto, pressupõe relações de poder, nas quais historicamente, existe prevalência de um sexo sobre o outro.

Não se trata de adotar uma perspectiva ou um olhar vitimizador em relação à mulher, o que já recebeu críticas importantes, mas destacar que a expressiva concentração deste tipo de violência ocorre historicamente sobre os corpos femininos e que as relações violentas existem porque as relações assimétricas de poder permeiam a vida rotineira das pessoas. (BANDEIRA, 2014)

Portanto, após discorrer sobre gênero e poder, oportuno se faz abordar a temática proposta, qual seja analisar a violência contra mulher sob tais perspectivas (gênero e poder).

\section{VIOLENCIA CONTRA A MULHER NAS PERSPECTIVAS DE GÊNERO E PODER}

De acordo com Saffioti (2004), violência de gênero é um conceito mais amplo, abrangendo vítimas como mulheres, crianças e adolescentes de ambos os sexos. Portanto, violência de gênero não significa necessariamente violência contra a mulher. Estes conceitos passaram a ser utilizados como sinônimos a partir do movimento feminista da década de 70 , que na luta contra a violência de gênero, passou a afirmar a expressão violência contra a mulher, já que esta é o alvo principal daquela (TELES; MELO, 2002).

Violência de gênero, portanto, pode ser compreendida como categoria mais ampla, compreendendo os homens também como vítimas da construção dos papéis sociais específicos a cada sexo, sem desconsiderar que o masculino se encontra situado no pólo positivo (BOURDIEU, 2005), dominador, nesta ideologia sexista. Assim como as mulheres, os homens ao desafiarem seus papéis de gênero, afastando-se do pólo masculino e aproximando-se, deste modo, do pólo oposto, do feminino - são vítimas de violência.

Em sentido mais abrangente, o sexo masculino é também vítima de violência de gênero na construção do ser tornar-se homem: dominador, forte, heterossexual, controlador, 
provedor, racional. Mas ao estar no pólo favorecido desta relação, encontra-se principalmente como sujeito ativo praticante desta violência, inclusive quando ela se dá contra pessoas de seu mesmo sexo. O homem quando sofre violência de gênero, a sofre para reagir, para tornar-se agressivo, dominador, violento. (CUNHA, 2014)

Segundo Teles e Melo, (2002) é de se conceber por violência de gênero a relação de poder de dominação do homem e de submissão da mulher. Essa relação demonstra que os papéis impostos às mulheres e aos homens, consolidados ao longo da história e reforçados pelo patriarcado e sua ideologia, induzem relações violentas entre os sexos e indica que a prática desse tipo de violência não é fruto da natureza, mas sim, do processo de socialização das pessoas.

O conceito de violência de gênero só pode ser entendido, seja em seu sentido mais amplo seja em seu sentido específico, como relação de poder de dominação do homem e de submissão da mulher, pois integra a ordem patriarcal de gênero (CUNHA, 2014). Em outras palavras, a violência de gênero é praticada contra a mulher no âmbito do processo histórico de dominação masculina, o qual visa submetê-la às regras de uma cultura patriarcal. (CARVALHO, 2012)

La violencia de género puede considerarse la más cruda manifestación de poder directo. Las motivaciones de un agresor suelen ser: 1) necesidad de control sobre la mujer, 2) sentimiento de poder, 3) evaluación de la independencia femenina como pérdida de control, 4) liberación de la rabia ante un ataque a su posición patriarcal, 5) desahogo vicario. La furia desencadenada por personas más fuertes suele desahogarse maltratando a personas más débiles. (MARINA, 2008)

Para Teles e Melo (2002), a violência de gênero pode ser entendida como violência contra a mulher. Embora o uso da expressão violência contra a mulher possa ter diversos significados, dependendo de suas implicações empíricas e teóricas, segundo Almeida (2007) seus variados usos semânticos têm, muitas vezes, sentidos equivalentes nas distintas nominações: violência contra a mulher, violência doméstica, violência intrafamiliar, violência conjugal, violência familiar e violência de gênero.

Essa diversidade de denominações é resultado da inexistência de uma única denominação e deve-se à complexidade do fenômeno estudado, à sua amplitude e à sua operacionalização, já que dependendo da área do conhecimento em que se percebe o problema, tem-se uma conceituação (ÂNGULO-TUESTA, 1997). Corroborando com esse 
pensamento, Dantas-Berger e Giffin (2005) afirmam que a delimitação conceitual do termo é apoiada numa ambiguidade terminológica, devido a não existência de consenso para nomear a violência praticada contra as mulheres.

Segundo as autoras, violência baseada em gênero, violência de gênero e violência contra mulheres são sinônimos, por serem mais abrangentes, abarcando nessa conjuntura todas as violências praticadas por homens contra as mulheres, pautadas numa relação de poder. As autoras ressaltam, no entanto, que por ocorrerem geralmente no âmbito familiar e/ou entre parceiros íntimos, têm-se como outras possibilidades denominar de violência doméstica ou intrafamiliar, mesmo que estas não caracterizam apenas eventos praticados contra mulheres. (DANTAS-BERGER; GIFFIN, 2005)

Conforme Heise (1994, p.47-48), a violência é "um fenômeno extremamente complexo, com raízes profundas nas relações de poder baseadas no gênero, na sexualidade, na auto identidade e nas instituições sociais" e que "em muitas sociedades, o direito (masculino) a dominar a mulher é considerado a essência da masculinidade”. Abordar a violência exige, portanto, confrontar essas definições de gênero e aumentar o poder e os recursos das mulheres. (GIFFIN, 1994)

Para disciplinar a violência de gênero, tem-se no Brasil, a Lei 11.340/2006, conhecida por Lei Maria da Penha, que possui como objetivo principal a superação da desigualdade entre o homem e a mulher, com o fim de preservar uma categoria de gênero, em que o ser mulher não se limita ao sexo biológico, mas se reporta ao modo de ser, ao estilo e modo de condução de vida, visando desnaturalizar as construções socioculturais que engessam os papéis do feminino e do masculino nas diferenças biológicas.

De acordo com Simioni e Cruz (2011), a Lei Maria da Penha retrata uma mudança de paradigma no enfrentamento da violência contra a mulher, ao trazer uma perspectiva de gênero para abordar da violência contra a mulher. $O$ caput do artigo $5^{\circ}$ traz o conceito fundamental de violência doméstica e familiar contra a mulher como sendo qualquer ação ou omissão baseada no gênero que possa causar a mulher morte, lesão, sofrimento físico, sexual ou psicológico e dano moral ou patrimonial.

O dispositivo destaca o quesito do gênero feminino ao entender que há uma carga cultural e histórica, reforçando o patriarcado, bem como a dominação do homem sobre a mulher, a qual tem o papel incutido de submissão àquele, havendo uma padronização de 
gênero social que desprivilegia a mulher, e que, por estar cingida nas estruturas da sociedade, acaba, ainda, por refletir no comportamento dos atores sociais, com relacionamentos sendo delineados pelo fator hierarquia de um sexo em detrimento de outro. (SANTOS; WITECK, 2006)

Os incisos I e II, do artigo $5^{\circ}$ da Lei Maria da Penha, coíbem a violência contra a mulher mais comum no Brasil, de acordo com os dados estatísticos, que é a violência doméstica e familiar, ainda que não se desconheça outras formas de violências. (SIMIONI; CRUZ, 2011) Uma das formas mais comuns de violência contra as mulheres é a praticada pelo marido ou um parceiro íntimo (GARCÍA-MORENO; HEISE, 2002), ou seja, quando os agressores são homens com os quais as mulheres se relacionam afetiva e sexualmente.

Os autores, nestes casos, conhecem bem as vítimas e seus pontos mais vulneráveis. Dominam a situação e sabem como e onde ameaçá-las, como espancá-las, humilhá-las e cometer outras práticas de agressão e lesão. (MENDES, 2013) O fato é que as mulheres, em geral, estão emocionalmente envolvidas com quem as vitimiza e dependem economicamente deles. Esta violência perpetrada por parceiro íntimo ocorre em todos os países, independentemente de grupo social, econômico, religioso ou cultural. (CASIQUE; FUREGATO, 2006)

De outra parte, o conceito de comunidade familiar proposta pela lei é amplo. Nele estão abarcados maridos, companheiros, namorados, amantes, filhos, pais, padrastos, irmãos, cunhados, tios e avós (com vínculos de consanguinidade, de afinidade ou por vontade expressa). Este conceito abrange uma variedade de laços de pertencimento no âmbito doméstico, inclusive as pessoas esporadicamente agregadas, visto que particularmente em casos de violência sexual, sobrinhas, enteadas, irmãs unilaterais que convivem na mesma casa, e até empregadas domésticas que dormem ou não na residência, podem sofrer com esse tipo de violência. (SIMIONI; CRUZ, 2011)

Esse dispositivo também é importante porque permite que a violência sexual contra mulheres ocorrida no âmbito doméstico e familiar saia da invisibilidade, assim como permite um tratamento jurídico-legal mais adequado à questão, no marco da compreensão da violência sexual como uma variante da violência baseada nas desigualdades de gênero. (SIMIONI; CRUZ, 2011) 
De acordo com Simioni e Cruz (2011), a existência de desigualdades nas relações de poder baseadas no gênero combinada com aspectos da vulnerabilidade social de um grande grupo de mulheres (somados aos marcadores de classe, raça/etnia e geração) foram alguns dos fatores determinantes para a construção de uma legislação nacional especialmente dedicada à coibição da violência doméstica e intrafamiliar.

Ao interpretar a lei, então, deve-se atentar aos padrões estereotipados sobre os papéis sexuais a serem exercidos diferente e desigualmente pelos homens e mulheres, que ainda limitam ou reduzem a capacidade da mulher de decidir ética e moralmente, ou seja, de exercer sua vontade. Os estereótipos geram falsas crenças e expectativas sobre o comportamento das pessoas. (FEIX, 2011)

Concorda-se, portanto, com a percepção de Gregori (1993) sobre o assunto, qual seja: a violência doméstica é fruto de uma dinâmica familiar violenta, sendo preciso superar a visão dualista e fixa dos papéis de gênero. Desta forma, a conflitualidade no âmbito doméstico deve ser compreendida como um fenômeno relacional, fazendo parte daquela cena os diversos sujeitos e atores sociais, para além de uma polarização reificada entre agressor e vítima.

Daí a importância da análise dos contextos e significados atribuídos por estes sujeitos. Nessa perspectiva, não se pode definir a violência como uma categoria a priori, mas configurada segundo as regras do espaço social no qual se manifesta. (SARTI, BARBOSA e SUAREZ, 2006)

\section{CONSIDERAÇÕES FINAIS}

No jogo social, a desigualdade de gênero e a violência contra mulher repousam sobre as bases do capitalismo excludente, indicando que a ruptura perpassa por políticas públicas diversas e conectadas, pois a desigualdade de gênero está no centro de radiação da manutenção do desequilíbrio de poder presente e normalizado na sociedade.

Percebe-se com isto que a desigualdade de gênero constitui-se em um dos eixos estruturantes da sociedade, entrelaçando-se com a de raça e a de classe, de forma que, juntas, complexificam-se e, quando tomadas em separado, apresentam especificidades. Acredita-se 
que só haverá uma real libertação, emancipação e empoderamento das mulheres quando houver, de fato, a superação da estrutura patriarcal e capitalista.

Desta forma, o gênero mostra-se estruturante da sociedade, sendo a violência contra a mulher fenômeno essencial à desigualdade de gênero, não só é produto social, como é fundante desta sociedade patriarcal, que se sustenta em relações de dominação e submissão. Portanto, não pode ser compreendida tão-somente como violência física, mas também como ruptura de qualquer forma de integridade da mulher.

\section{REFERÊNCIAS}

ALBERDI, Inês; MATAS, Natália. La violencia doméstica: informe sobre los malos tratos a mujeres en España. Barcelona: Fundación La Caixa, 2002.

ANDRADE, Vera Regina Pereira de. Sexo e gênero: a mulher e o feminino na criminologia e no sistema de justiça criminal. 2004.

ÂNGULO-TUESTA, Antonia de Jesús. Gênero e violência no âmbito doméstico: a perspectiva dos profissionais de saúde. 1997. 151f. Dissertação (Mestrado em Ciências na área de Saúde Pública) - Departamento de Ciências Sociais, Fundação Oswaldo cruz, Escola Nacional de Saúde Pública, Rio de Janeiro, 1997.

BANDEIRA, Lourdes Maria. Violência de gênero: a construção de um campo teórico e de investigação. Sociedade e Estado, v. 29, n. 2, p. 449-469, 2014.

BOURDIEU, Pierre. A dominação masculina. Tradução Maria Helena Kuhner. 2. ed. Rio de Janeiro: Bertrand Brasil, 2002, 2005.

BRASIL. Lei n ${ }^{\circ}$ 11.340, de 7 de agosto de 2006. Diário Oficial da União. Lei Maria da Penha. Cria mecanismo para coibir a violência doméstica e familiar contra a mulher. Brasília: Casa Civil, 8 ago. 2006. Seção 1, p. 1.

CABRAL, Francisco; DÍAZ, Margarita. Relações de gênero. In: SECRETARIA MUNICIPAL DE EDUCAÇÃO DE BELO HORIZONTE; FUNDAÇÃO ODEBRECHT. Cadernos afetividade e sexualidade na educação: um novo olhar. Belo Horizonte: Gráfica e Editora Rona Ltda., p. 142-150, 1998.

CARVALHO, Patrícia Cunha Barreto de; GOLDHAR, Tatiane Gonçalves Miranda. A mediação como instrumento de contenção da violência doméstica. 2012. In: Revista da Esmese. Aracaju: ESMESE/TJ, n 17, p.101-110, 2012.

CASIQUE, Leticia; FUREGATO, Antonia Regina Ferreira. Violência contra mulheres: reflexões teóricas. In: Revista Latino-Americana de Enfermagem, v. 14, n. 6, 2006.

COSTA, Renata; MADEIRA, Maria; SILVERA, Clara. Relações de gênero e poder: tecendo caminhos para a desconstrução da subordinação feminina. $17^{\circ}$ Encontro nacional da rede feminista e norte e nordeste de estudos e pesquisa sobre a mulher e relações de gênero, v. 17, p. 222-240, 2012. 
CUNHA, Barbára Madruga da. Violência contra a mulher, direito e patriarcado: perspectivas de combate à violência de gênero. In: Jornada De Iniciação Científica, v. 16, p. 149-170, 2014.

DANTAS-BERGER, Sônia Maria; GIFFIN, Karen. A violência nas relações de conjugalidade: invisibilidade e banalização da violência sexual? Cadernos de Saúde Pública, Rio de Janeiro, v. 21, n. 2, p. 417-425, mar./abr. 2005.

FARIA, Josiane Petry. A participação feminina na transformação da história patriarcal: dimensões poder e desenvolvimento como liberdade. In: Revista Direitos Humanos e Democracia, v. 5, n. 10, p. 2-20, 2017.

FEIX, Virgínia. Formas de violência contra a mulher - artigo 7. In: CAMPOS, Carmen Hein de. (Org.). Lei Maria da Penha comentada em uma perspectiva jurídico-feminista. Rio de Janeiro: Lumen Juris, 2011, p.201-213.

FOUCAULT, Michel. Microfísica do poder. Tradução Roberto Machado. Rio de Janeiro: edições Graal, 1979.

GARCÍA-MORENO, Cláudia; HEISE, Lori. Violência perpetrada por parceiros íntimos. In: World Health Organization. World Report on violence and Health. Genebra: OMS. p. 91-121, 2002.

GIFFIN, Karen. Gender violence, sexuality, and health. In: Cadernos de Saúde Pública, v. 10, p. S146-S155, 1994.

GOMES, Nadielene Pereira; DINIZ, Normélia Maria Freire; ARAUJO, Anne Jacob de Souza e COELHO, Tâmara Maria de Freitas. Compreendendo a violência doméstica a partir das categorias gênero e geração. In: Acta Paul Enferm, v. 20, n. 4, p. 504-8, 2007.

GREGORI, Maria Filomena. Cenas e queixas: um estudo sobre mulheres, relações violentas e a prática feminista. São Paulo: Paz e terra, 1993.

HEBERLE, Viviane Maria. Questões de gênero e identidade no discurso da mídia. In: GRIGOLLETTO, Marisa e CARMAGNANI, Ana Maria G. (Org.). Inglês como língua estrangeira: identidade, práticas e textualidade. São Paulo: Humanitas, 2001.

HEISE, Lori. Violence Against Women: The Hidden Health Burden. Relatório Preparado para o Banco Mundial. (Mimeo.) World Bank Discussion Papers 255, Washington, D.C.: World Bank, 1994.

LAURETIS, Teresa. A tecnologia do gênero. In: HOLLANDA, Heloisa Buarque de.

Tendências e impasses: o feminismo como crítica da cultura. Rio de Janeiro: Rocco, 1994.

LOURO, Guacira Lopes. Gênero, sexualidade e educação: uma perspectiva pós-estruturalista. Petrópolis, Rio de Janeiro: Vozes, 1997.

MARINA, José Antonio. La pasión del poder: teoría y práctica de la dominación. 2008.

MENDES, Soraia da Rosa. Os direitos fundamentais das mulheres à autodeterminação e à proteção como limites ao poder punitivo: reflexões sobre a criminalização do aborto no Projeto de Novo Código Penal e sobre a proibição de proteção deficiente no Supremo Tribunal Federal. In: Revista Brasileira de Estudos Constitucionais [recurso eletrônico], 2013. 
NOGUEIRA, Conceição. Um novo olhar sobre as relações sociais de gênero: feminismo e perspectivas críticas na psicologia social. Fundação Calouste Gulbenkian, 2001.

OLIVEIRA, Anay Stela de; KNÖNER, Salete Farinon. A construção do conceito de gênero: uma reflexão sob o prisma da psicologia. Trabalho de Conclusão de Curso. Blumenau: FURB, 2005.

PERROT, Michele. Os excluídos da história: operários, mulheres e prisioneiros. Rio de Janeiro: Paz e Terra, 1988.

PRAUN, Andreia Gonçalves. Sexualidade, gênero e suas relações de poder. Revista Húmus, v. 1, n. 1, 2011.

QUEIROZ, Fernanda Marques de. Não se rima amor e dor: cenas cotidianas de violência contra a mulher. Mossoró, RN: UERN, 2008.

RUBIN, Gayle. The Traffic in Women. Notes on the Political Economy of Sex. In: REITER, Rayna (ed.) Toward an Anthropology of Women. New York, Monthly Review Press, 1975.

SAFFIOTI, Heleieth Iara Bongiovani. Gênero, patriarcado, violência. São Paulo: Editora Fundação Perseu Abramo, 2004.

Rearticulando Gênero e Classe Social. In:

BRUSCHINI, Cristina; COSTA, Albertina de Oliveira. Uma questão de Gênero. Rio de janeiro: Rosa dos Tempos; São Paulo: Fundação Carlos Chagas, 1992.

SANTOS, Ana Paula Coelho Abreu dos; WITECK, Guilherme. Violência doméstica e familiar contra a mulher. In: Seminário Internacional Demandas Sociais e Políticas Públicas na Sociedade Contemporânea, 2006.

SARTI, Cynthia A.; BARBOSA, Rosana M.; SUAREZ, Marcelo M. Violência e Gênero: vítimas demarcadas. In: PHYSIS: Revista de Saúde Coletiva, Rio de Janeiro, n. 16, vol. 2, p. 167-183, 2006.

SCOTT, Joan. Gênero: uma categoria útil de análise histórica. In: Educação e Realidade. Porto Alegre, v.16, n.2, p., 5-22, jul/dez., 1995.

SIMIONI, Fabiane; CRUZ, Rúbia Abs da. Da violência doméstica e familiar - artigo $5^{\circ}$. In: CAMPOS, Carmen Hein de (Org). Lei Maria da Penha Comentada em uma perspectiva jurídico-feminista. Rio de Janeiro: Lumen Juris, 2011.

STREY, Marlene Neves. Violência e gênero: um casamento que tem tudo para dar certo. Violências e gênero: coisas que a gente não gostaria de saber. Porto Alegre: EDIPUCRS, p. 47-69, 2001.

TELES, Maria Amélia de Almeida. MELO, Mônica de. O Que é Violência contra a Mulher. São Paulo: Brasiliense, 2002.

TORRES, Iraildes Caldas. A perspectiva de poder em Foucault e suas conexidades com as relações de gênero. Pensamento \& Realidade. Revista do Programa de Estudos PósGraduados em Administração-FEA. v. 9, 2001.

VARIKAS, Eleni. Jornal das damas: feminismo no sec. XIX na Grécia. In: Seminário relações sociais de gênero versus relações de sexo. São Paulo: FFLCH/USP. 1989. 